\title{
Improvement and Application of Key Tools for Hydraulic Jet Fracturing
}

\author{
Yibo Zhang \\ Daqing Oilfield Production Engineering Research Institute, Daqing 163453, China
}

\begin{abstract}
Aiming at the problems of poor reliability, low construction efficiency, and short service life of fracturing string in the application of hydraulic jet technology in Daqing Oilfield, targeted research has been carried out on key tools such as rubber cylinder, slip, and nozzle.A unidirectionally-sealing rubber cylinder adopting composite sealing method was designed. The rubber cylinder could bear the pressure of $80 \mathrm{MPa}$ and temperature resistance of $150^{\circ} \mathrm{C}$ under the setting force of $20 \mathrm{kN}$, with tensile strength increased by $23 \%$ and residual deformation rate less than $3 \%$, showing good overall sealing performance and recovery. The finite element method was used to optimize the structural parameters, materials and process of the slip to increase the ability of slips to withstand alternating loads by 1.5 times. The arc-shaped nozzle was improved to reduce the pressure drop and increase the jet density. By improving the performance indicators of key tools, the optimized fracturing string could meet the construction requirements of low setting force, high sealing pressure difference, and repeated setting and fracturing. The improved technical string was applied to section 3459 of well 218 well in the field, with the success rate reaching $100 \%$. The large-scale application of the improved fracturing string satisfied the construction requirements for large-scale volume fracturing of the for the $51 / 2$ " inch casing new well completion in the low-permeability and tight reservoirs of Daqing Oilfield.
\end{abstract}

Keywords: Hydraulic jet; fracturing string; packer; nozzle; perforation.

\section{Introduction}

Hydraulic jet fracturing technology with coiled tubing is a new and efficient reservoir reconstruction technology for horizontal wells. It uses high-speed sand-carrying liquid jets to penetrate through the casing and cement ring to achieve combined operation of perforation and fracturing, so as to achieve the large-scale volume reconstruction of reservoirs [1-3]. This process has the advantages of short operation cycle, less times of lifting and lowering the string, and low construction cost. It is gradually becoming one of the main fracturing processes for horizontal well development wells in the periphery of Daqing Oilfield. However, there are still some problems to be solved in the process of field application. Specifically, it is difficult to control the setting and releasing of the packer, deformation and damage of the rubber cylinder, long perforation time of the spray gun, short perforation distance, and serious damage to the outer surface of the spray gun by erosion and backsplash abrasion ${ }^{[4]}$. Aiming at the above problems, this paper aims to optimize the hydraulic jet fracturing tools and improves the technical indicators and reliability of the tools.

\section{Improvement of the structure of key tools for hydraulic jet fracturing}

\subsection{Improvement of the structure of the bottom seal rubber cylinder of the packer}

Aiming at the problems that the traditional three-rubber cylinder and the compression-type single-rubber cylinder with a V-shaped angle structure at the end have the disadvantages of low pressure capacity, poor temperature resistance, releasing after repeated setting, and easy damage, an unidirectionally-sealing pressure-bearing rubber cylinder with pressure cap and tapered shoulder is designed. The pressure cap limits the pressure-bearing deformation of the rubber cylinder and improves the releasing performance of the rubber cylinder. The tapered shoulder reduces the setting force and improves the pressure-bearing performance. At the same time, we improve the high tensile strength rubber formula and its compatible additives, and research the secondary molding and vulcanization process of the rubber cylinder. Through multiple rounds of $150^{\circ} \mathrm{C}$ oil immersion experiments on the structure, the new structure has achieved the pressure bearing of $80 \mathrm{MPa}$, with tensile strength increased by $23 \%$,

\footnotetext{
* Corresponding author: yibozhang@petrochina.com.cn
} 
the residual deformation rate less than $3 \%$ and the fatigue repeated 80 times, under $20 \mathrm{kN}$ setting force. The overall sealing performance and recovery of the rubber cylinder are good, and meet the needs of on-site volume fracturing construction.

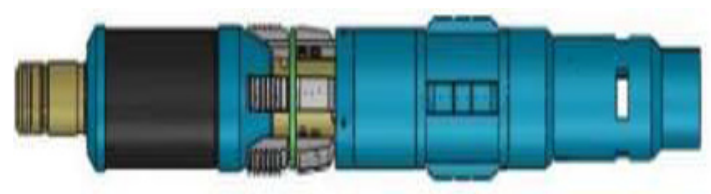

Fig 1. Structure schematic diagram of packer

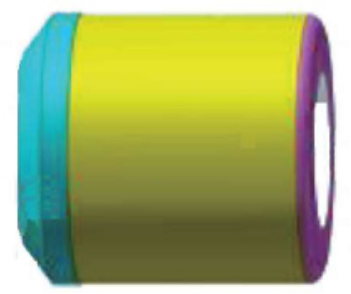

Fig 2. 3D diagram of rubber cylinder

\subsection{Bottom seal slip structure of the packer and material optimization}

Horizontal well completions mostly use high-hardness P110 steel-grade casing, which has higher requirements for the rationality of slip structure, material toughness and hardness. For the cases where slip's tooth tip is flattened or the slip body is broken, leading to the failure of covering the casing, the ANSYS finite element software is used to optimize the design of the slip structure. It can be seen from the axial stress distribution law of slip teeth that there is obvious stress concentration near the side of the slip. Combined with the results of numerical analysis, it is determined that the number of slip teeth is 7 , the tooth width is $8 \mathrm{~mm}$, the arc angle at the contact with the hoop is $2^{\circ}$, and the arc angle of the tooth bottom is $1^{\circ}$, which improves the stress state, reduces stress concentration, and ensures that the slip can fully anchor the casing. The ultra-high-strength and corrosion-resistant A-100 steel is adopted, the carburizing and laser treatment processes are used, so that the slip has high tensile strength, hardness and fatigue resistance, as well as high fracture toughness and ductility, with the ability to withstand alternating loads being increased by 1.5 times.

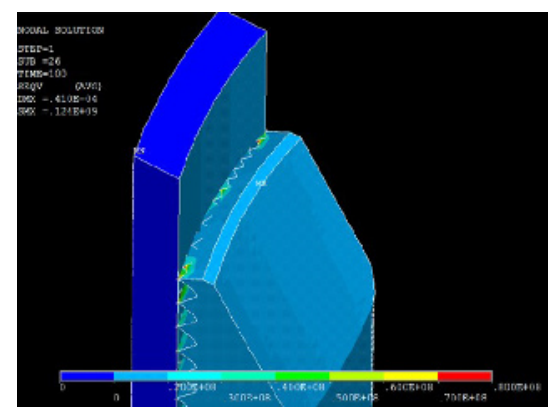

Fig 3. Mises stress distribution of $3 \mathrm{D}$ contact

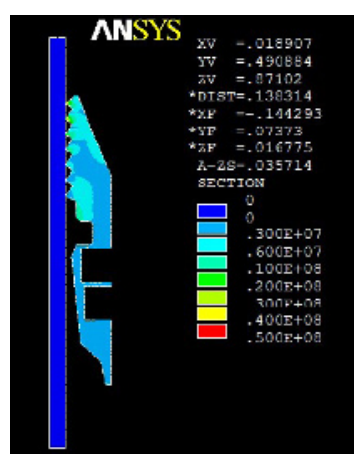

Fig 4. Mises stress distribution of axial contact

\subsection{Improvement of the nozzle structure of built- in spray gun}

As a key component of jet formation, the structural characteristics of the nozzle directly affect the quality of the jet. Aiming at the problems of long jet time, poor concentration, and large pressure loss under the conditions of high displacement and large sand fracturing, the single-phase flow model and multi-phase flow model are used to simulate the jet performance of the coneshaped and curve-shaped nozzles, respectively. The single-phase flow model adopts the k-epsilon turbulence model and the simple algorithm, and uses the secondorder upwind style to improve the calculation accuracy ${ }^{[5-}$ 6]. The multi-phase flow model adopts Euler model and couple coupling algorithm.

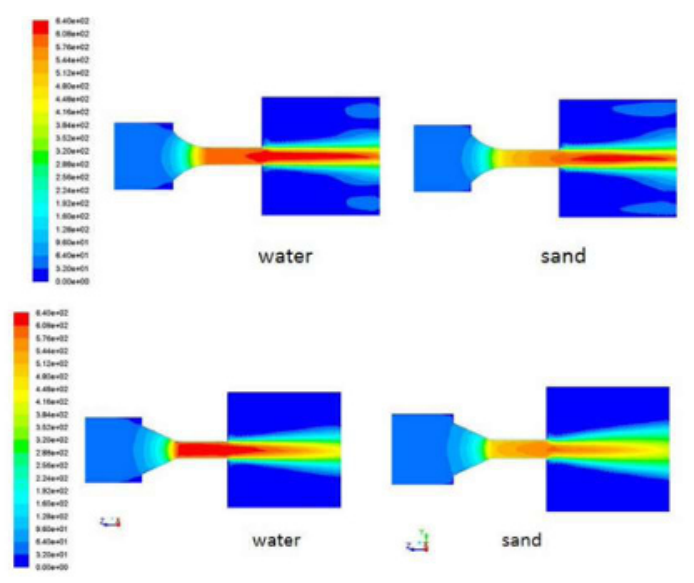

Fig 5. Contours of sand phase and water phase velocity

The simulation results of the two-phase flow model show that the jet density of the arc-shaped nozzle is significantly better than that of the cone-shaped nozzle. The orthogonal analysis of the outlet diameter, the length of the straight column and the radius of the inlet curve shows that the jet performance (jet impact force and density) of the arc-shaped nozzle is mainly affected by the outlet diameter, followed by the length of the straight column. 


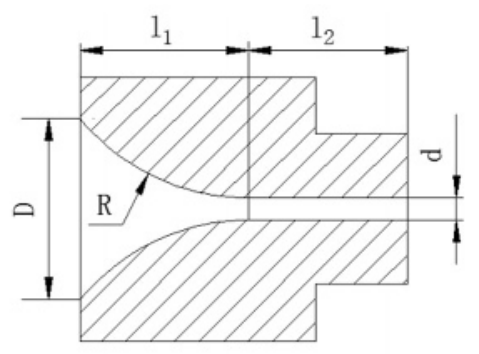

Fig 6. The structure of curved-shape nozzle

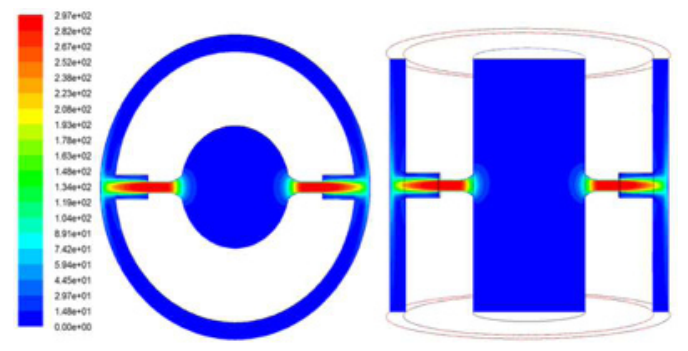

Fig 7. Jet velocity distribution at the nozzle

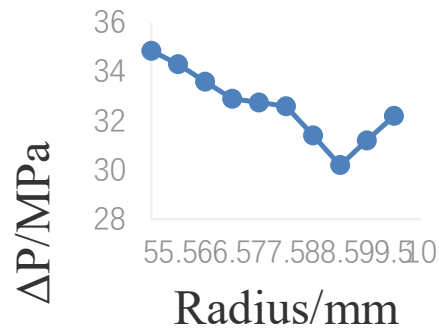

Fig 8. The influence of the inlet curve radius on the differential pressure

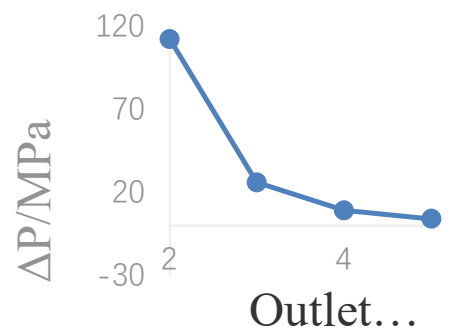

Fig 9. The influence of the outlet diameter on the differential pressure

We select the $8.5 \mathrm{~mm}$ inlet curve radius corresponding to the minimum pressure difference between the nozzle inlet and the outlet, and increase the nozzle outlet diameter as much as possible under the premise of meeting the jet velocity. Then, we choose the outlet diameter $d$ in the range of $4.5-5 \mathrm{~mm}$. In order to control the jet pressure difference while ensuring a certain jet density, the length $l_{2}$ of the straight column is selected to be $8-11 \mathrm{~mm}$. In order to reduce the difficulty of tool processing, the inlet diameter $\mathrm{D}$ is selected as $2 \mathrm{~d}$. The results of digital simulation and field tests have proved that we can effectively reduce the pump pressure, ensure sufficient jet impact force, and increase the jet density of the nozzle by applying arc-shaped nozzle and selecting reasonable range of structural parameters.

Table 1. Three Scheme comparing.

\begin{tabular}{|c|c|c|c|}
\hline $\begin{array}{c}\text { Optimal } \\
\text { parameters }\end{array}$ & $\begin{array}{c}\text { Outlet } \\
\text { diameter } \\
(\mathrm{mm})\end{array}$ & $\begin{array}{c}\text { Straight } \\
\text { column } \\
(\mathrm{mm})\end{array}$ & $\begin{array}{c}\text { Entrance } \\
\text { curve } \\
\text { Radius } \\
(\mathrm{mm})\end{array}$ \\
\hline $\begin{array}{c}\text { Optimal } \\
\text { pressure Loss }\end{array}$ & $\mathrm{d} \geq 4.5$ & $1_{2} \leq 11$ & 8.5 \\
\hline $\begin{array}{c}\text { Optimal jet } \\
\text { velocity }\end{array}$ & $\mathrm{d} \leq 5.0$ & $/$ & $/$ \\
\hline $\begin{array}{c}\text { Optimal jet } \\
\text { density }\end{array}$ & $\mathrm{d} \geq 4$ & $1_{2} \geq 8$ & $/$ \\
\hline $\begin{array}{c}\text { Optimal jet } \\
\text { quality }\end{array}$ & $4.5 \leq \mathrm{d} \leq 5.0$ & $8 \leq \mathrm{l}_{2} \leq 11$ & 8.5 \\
\hline
\end{tabular}

\section{Field application}

Well Gp 1 is a horizontal well located in the Putaohua structure of the Daqing Placanticline in the central depression area of the Songliao Basin. The field test was carried out in Well Gaoping 1 using the coiled tubing hydraulic jet fracturing technology . The technical string was composed of safety joint, centralized spray gun, packer, positioner, and guide head. Within construction time of 42 hours, we completed 19-section fracturing construction in one procedure, with high construction pressure of $62 \mathrm{MPa}$, maximum displacement of 6.7 $\mathrm{m}^{3} / \mathrm{min}$, liquid volume of $8814.5 \mathrm{~m}^{3}$, sand volume of $830.5 \mathrm{~m}^{3}$, the cumulative number of string setting and releasing reaching 52 times, $100 \%$ success rate. This has created a new record for the number of fracturing sections, liquid volume, sand volume and construction efficiency of one procedure in Daqing Oilfield. In 2018-2020, the coiled tubing hydraulic jet annulus sanding fracturing process was promoted and applied to 3459 sections of 218 wells. The technical string showed temperature resistance of $120^{\circ} \mathrm{C}$, pressure resistance of $70 \mathrm{MPa}$, tubing displacement of $1 \mathrm{~m}^{3} / \mathrm{min}$, and annulus displacement 10 $\mathrm{m}^{3} / \mathrm{min}$, and 20 sections fracturing within one procedure in average, which solved the problems of high environmental pressure and low construction efficiency of conventional tubing fracturing technology in peripheral low-permeability tight reservoirs, and improved single well productivity and potential reservoir production.

\section{Conclusion}

1. An unidirectionally-sealing rubber cylinder with a composite sealing method and a tapered shoulder protection structure are designed to achieve the technical indicators of $80 \mathrm{MPa}$ pressure and temperature resistance of up to $150^{\circ} \mathrm{C}$ under $20 \mathrm{kN}$ setting force. The overall sealing performance and recoverability of the rubber cylinder are good, so that the packer has good setting and releasing performance. 
2. The finite element method is used to optimize the slip structure parameters, ultra-high-strength materials are selected and carburizing and laser processing techniques are used to improve the stress state, reduce stress concentration, and improve the slip's ability to withstand alternating loads.

3. The arc-shaped nozzle with better jet performance is selected and reasonable structural parameters are selected, which can effectively reduce the pump pressure, ensure sufficient jet impact force, and improve the jet density of the nozzle.

4. Through tool improvement and matching, the coiled tubing hydraulic jet fracturing technology has been improved. From 2018 to 2020, the improved fracturing technology has been promoted and applied to 3459 sections of 218 wells. The technical string showed temperature resistance of $120^{\circ} \mathrm{C}$, pressure resistance of 70 $\mathrm{MPa}$, and 20 sections fracturing within one procedure in average, which could meet the construction requirements of new wells for high-efficiency volumetric fracturing of $51 / 2$ " casing cementing completions in low-permeability tight reservoirs.

\section{Acknowledgments}

We greatly appreciate the assistance in terms of the theory, technology and experiment of this paper provided by the Oil Production Engineering Research Institute of Daqing Oilfield.

\section{References}

1. HUANG Zhongwei, LI Gensheng, WANG Yongzhang, et al. Hydra-jet fracturing applied in a well with three-layercasings [J]. Oil Drilling \& Production Technology, 2012, 34(5): 122-124.

2. WANG Jinyou, XU Guowen, LI Lin, et al. Technology of coiled tubing abrasive perforating and annulus fracturing [J]. Oil Field Equipment, 2016, 45(5): 69-72.

3. WANG Fengshan, ZHANG Shujin, WANG Wenjun, et al. New development of horizontal well fracturing stimulation technologies for low-permeability reservoirs in Daqing [J]. Petroleum Geology \& Oilfield Development in Daqing, 2009, 28(5): 234238.

4. XU Guowen. Numerical simulation research of coiled tubing hydraulic jet erosion $[\mathrm{J}]$. Oil Field Equipment, 2016, 45(6): 12-15.

5. FU Dangang, LI Xianwen, REN Yong, et al. Application of hydraulic jet perforation in oilfield development [J]. Special Oil \& Gas Reservoirs, 2011, 18(3): 97-99.

6. SURJAATMADJA J B, BEZANSON J, LINDSAY S D. New hydra-jet tool demonstrates improved life for perforating and fracturing applications [R]. SPE113722, 2008. 